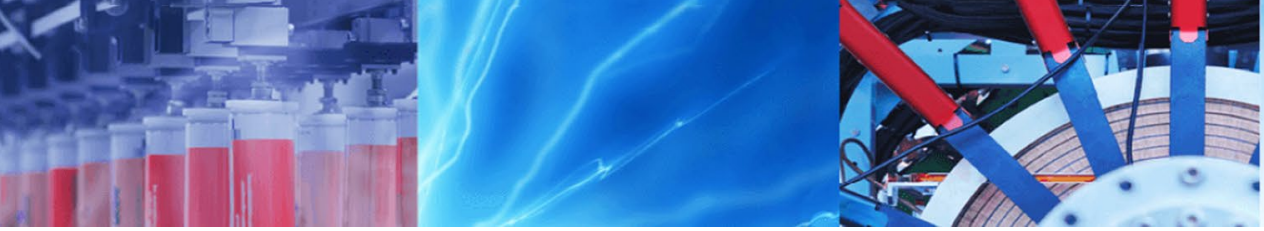

Review Paper

\title{
Electrical and thermal properties of PANI-Mmt nanocomposites in strongly acidic aqueous media
}

\author{
Youcef Hattab ${ }^{1} \cdot$ Nassira Benharrats ${ }^{1}$
}

(c) Springer Nature Switzerland AG 2019

\begin{abstract}
Polymer nanocomposite have presented a growing importance in many uses such as the higher protection of steel from corrosion, lifelong thermal and electrical performance of their nanocomposite due to their morphological improvements with nanocharges hence become an alternative to pure polymers. The nanocomposites are mixed materials synthesized by polymeric matrix with small percentage of montmorillonites $(\mathrm{Mmt})$ as inorganic reinforcement which can be recycled and not toxic. The dispersion of Mmt is facilitated by the organophilisation of their structure by alkylammonium. It is a question of following the evolution of the electrical conductivity and thermal stability of nanocomposite according to time for samples aged in strongly acidic solutions at various temperatures. Fractions of products will be taken regularly and characterized by FTIR-UV, RX and GPC. Conductivity will be followed by the four probe method. The study will be followed by the evaluation of morphology by microscopy and the thermal stability by DSC-TG.
\end{abstract}

Keywords Nanocomposite $\cdot$ PANI $\cdot$ Mmt $\cdot$ Electrical conductivity $\cdot$ Thermal stability

\section{Introduction}

Inorganic-polymer nanocomposite is considered as a new class of materials with better applications in electrical energy storage, gas sensors, anticorrosion, barrier properties, with the increased thermal properties [1-9]. The conjugated conducting polymers such as polyaniline (PANI) and polypyrrole have been studied extensively investigated due to their higher electrical properties and environmental stability which can be modified by changing oxidation state of the main chain and protonation mechanism when the doping of PANI is carried out using hydrochloric acid [10-15]. Actually, the PANI and their derivatives have been widely used in anticorrosive coatings of steel [16-24]. However, PANI has restricted uses as in the case of transport of the electron due to its immiscibility with the other solvents and the non-conducting polymers. But the development of the characteristics such as thermal, mechanical, and the anticorrosion of PANI could be possible with in situ polymerization of the PANI charged by nanolayers [25-27].

The object of this work is to study the electrical conductivity and thermal stability of nanocomposite (PANI-Mmt) in strict conditions.

In the first part of our manuscript we started with the synthesis and characterization of the polyaniline and nanocomposite by simple methods then we started the degradation of these materials in corrosive mediums. Different analysis techniques such as IR, AFM UV, TEM, AFM and SEM were used for the characterization of prepared samples. Then we showed the thermal stability of the materials in the corrosive mediums by using several thermal techniques. The last part describes evolution of conductivity according to conditions applied using electrical resistivity four probe method.

$\triangle$ Youcef Hattab, Hattab_Youcef@yahoo.fr | 'LPPMCA, Faculty of Chemistry, Université des Sciences et Technologie d'Oran Mouhamed Boudiaf, BP 1505, Al Mnaouer, 31000 Oran, Algeria.

SN Applied Sciences (2019) 1:750 | https://doi.org/10.1007/s42452-019-0703-1 
Fig. 1 Synthetic reaction scheme of PANI-ES

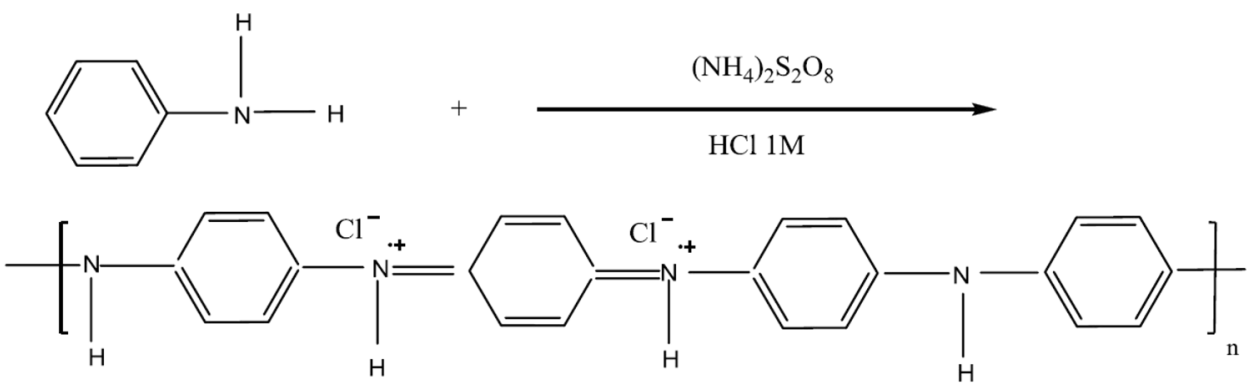

\section{Materials and methods}

\subsection{Synthesis of the polyaniline}

The various optimization of molar ratio of oxidant/aniline $(0.25,2.5$ and 4$)$ and temperatures $\left(0^{\circ} \mathrm{C}, 10^{\circ} \mathrm{C}\right.$ and $\left.20^{\circ} \mathrm{C}\right)$ were studied. Polyaniline was prepared by the oxidation of $0.5 \mathrm{M}$ aniline hydrochloride with $0.2 \mathrm{M}$ ammonium peroxydisulfate, started at $10^{\circ} \mathrm{C}$. A part of the product was deprotonated in $1 \mathrm{M}$ of excess ammonium hydroxide to yield the corresponding PANI base (Fig. 1).

\subsection{Synthesis of PANI/Mmt nanocomposites}

\subsubsection{Intercalation of the sodic montmorillonite with an organic molecule}

The elaboration of nanocomposite is conditioned by a complete dispersion of the silicates layer in the polymer matrix in order to increase the interactions between these two phases $[28,29]$. The sodic clay (montmorillonite KSF, Aldrich) is processed by alkylammonium salt which gives an organophile character with the cationic exchange $\left(\mathrm{Na}^{+}\right)$with the ammonium cations. For these syntheses we have chosen as agent of organophilization; the bromide of hexadecyltrimethylammonium (HDTMAB) a cationic surface active agent of formula: $\left(\mathrm{H}_{3} \mathrm{C}-\left(\mathrm{CH}_{2}\right)_{15}-\mathrm{N}+-\left(\mathrm{CH}_{3}\right)_{3}, \mathrm{Br}\right)$. Five grams of sodic montmorillonite is mixed with $3 \mathrm{~mm} \mathrm{~mol} / \mathrm{g}$ of HDTMAB, the inorganic/organic mixture is added to $250 \mathrm{ml}$ of distilled water, the montmorillonite here present, therefore, excellent inflating properties in suspension, better aptitudes for a cationic exchange. He mixture is placed in a trial balloon plunged in oil bath at $80^{\circ} \mathrm{C}$ under magnetic stirring [3000 rpm (rate per $\mathrm{min}$ )] for $4 \mathrm{~h}$ to ensure that the reactions be completed. After the cationic exchange, the suspension is filtered, the recuperated organophilized montmorillonite is rinsed with distilled water to eliminate the bromide ions, it is then dried, pounded and sifted.

\subsubsection{Synthesis of nanocomposites}

About $5 \%$ organoclay was added to $100 \mathrm{ml}$ of $1 \mathrm{M} \mathrm{HCl}$ (Biochem) solution. It was stirred for $1 \mathrm{~h}$ and kept overnight. PANI/Mmt nanocomposites were prepared by the initial insertion of aniline ( $99 \%$, Merck), into the colloidal suspension with room temperature during $24 \mathrm{~h}$ under magnetic stirring to intercalate the monomer in the space of clay. The mixture is brought to $5^{\circ} \mathrm{C}$ in a bath of ice. When this temperature is reached, the ammonium persulfate $\left(\left(\mathrm{NH}_{4}\right)_{2} \mathrm{~S}_{2} \mathrm{O}_{8}\right)$ dissolved in $100 \mathrm{ml}$ of aqueous solution of $1 \mathrm{M} \mathrm{HCl}$ (molar ratio aniline/oxidant equal to 4 to obtain good electrical conductivity), was added drop by drop to the suspension Mmt-aniline. The reaction was stopped after $8 \mathrm{~h}$. The final nanocomposite was recovered by filtration, washed with water until the filtrate was colourless. The precipitate was filtered with methanol and then an acetone to remove the oligomeric impurities [30,31], excess oxidant and residual aniline monomer.

\subsubsection{Degradation of the nanocomposites in the corrosive conditions}

After the synthesis of PANI/Mmt nanocomposites, we prepared solutions concentrated with $5 \mathrm{M} \mathrm{HCl}$ then we put $3 \mathrm{~g}$ of nanocomposite in $30 \mathrm{ml}$ of this concentrated solution at temperature of $80^{\circ} \mathrm{C}$ under conditions described in Table 1.

\subsection{Characterizations}

The infra-red analysis of Nanocomposite were realized in laboratory materials at the university of Oran by the spectrometer ALPHA BRUKER Optik (2000-600 nm), It is necessary to make a heat dried polymer powders at $65^{\circ} \mathrm{C}$, for $24 \mathrm{~h}$ then to convert them into $\mathrm{KBr}$ pellets. The thermal characterizations are made using TG-DSC SETARAM LABSYS Evo, It is necessary just before the polymer powder is dried, to raise the temperature with a step of $10^{\circ} \mathrm{C}$ until the temperature $850^{\circ} \mathrm{C}$ is reached. The identification by 
Table 1 Degradation of nanocomposites in corrosive conditions

\begin{tabular}{llllll}
\hline Sample & $\begin{array}{l}\text { Degradation } \\
\text { period (months) }\end{array}$ & $\begin{array}{l}\text { Degradation tem- } \\
\text { perature }\left({ }^{\circ} \mathrm{C}\right)\end{array}$ & $\begin{array}{l}\text { Initial } \\
\text { masse }(\mathrm{g})\end{array}$ & $\begin{array}{l}\text { Masse after deg- } \\
\text { radation }(\mathrm{g})\end{array}$ & $\begin{array}{l}\text { Type of } \\
\text { media } \\
(30 \mathrm{ml})\end{array}$ \\
\hline PANI 6.1.80 & 1 & 80 & 3 & 2.81 & $\mathrm{H}_{2} \mathrm{SO}_{4}$ \\
PANI 6.6.80 & 6 & 80 & 3 & 2.56 & $\mathrm{H}_{2} \mathrm{SO}_{4}$ \\
PANIEB 6.6.80 & 1 & 80 & 3 & 2.81 & $\mathrm{KOH}$ \\
PANIEB 6.6.25 & 6 & 25 & 3 & 2.70 & $\mathrm{HCl}$ \\
NanoPANI6.1.80 & 1 & 80 & 3 & 2.85 & $\mathrm{HCl}$ \\
NanoPANI6.2.80 & 2 & 80 & 3 & 2.75 & $\mathrm{HCl}$ \\
NanoPANI6.3.80 & 3 & 80 & 3 & 2.70 & $\mathrm{HCl}$ \\
NanoPANI6.4.80 & 4 & 80 & 3 & 2.69 & $\mathrm{HCl}$ \\
NanoPANI6.6.80 & 6 & 80 & 3 & 2.68 & $\mathrm{HCl}$ \\
\hline
\end{tabular}

Fig. 2 Percentage of mass loss depending of the aging time

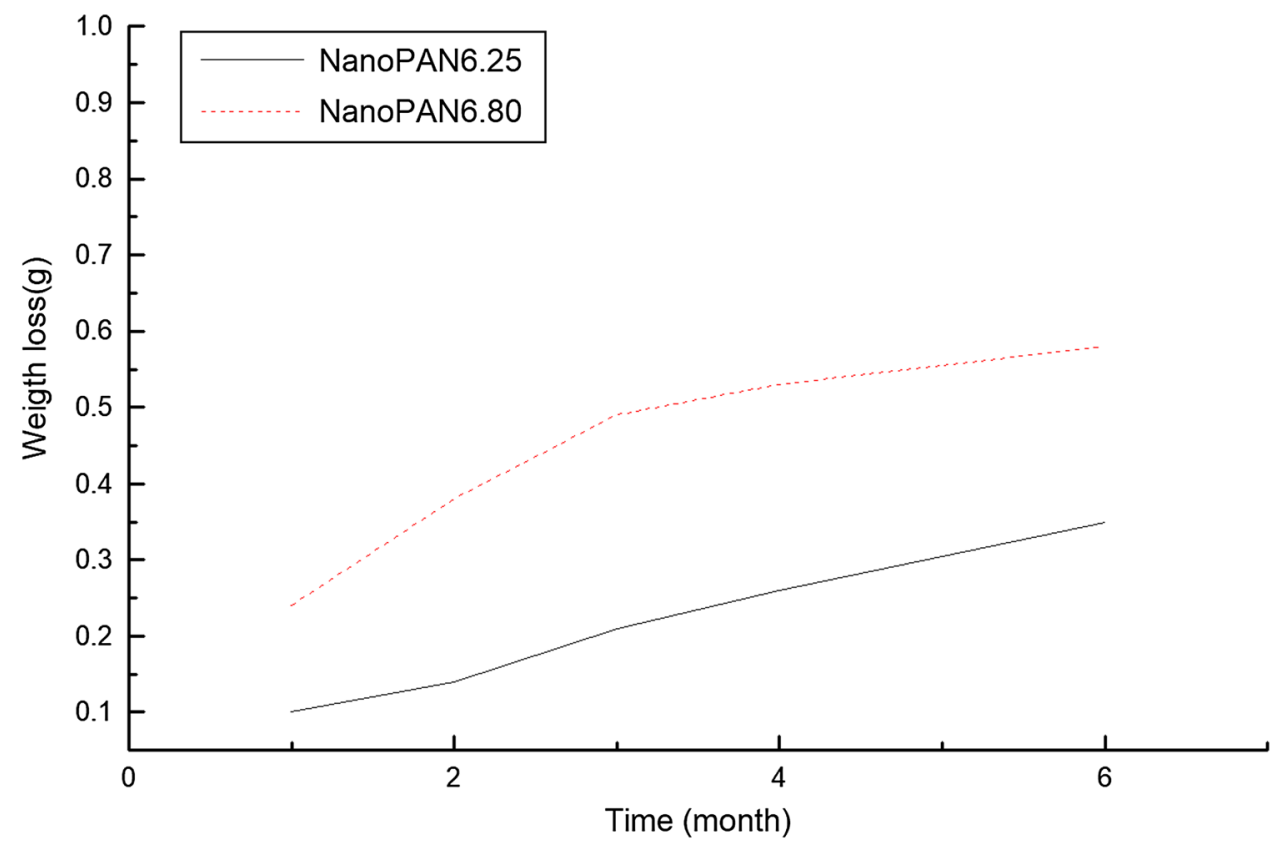

MEB is made on powder samples and pellets but the AFM on pastille with a BRUKER microscope.

The determination of the PANI structure with UV is made by a spectrometer ANALYTIC JENA Specord 210 and the structural of the nanocomposite were determined by a XRD (X-ray diffraction) with diffractometer INAL (the sample is powder: one selected the interval theta $=0-40$ as well as the step $=2$ ).

Finally an electrical conductivity test is made by the four point probe method, it is necessary to dry the polymer powders $24 \mathrm{~h}$ before at $65^{\circ} \mathrm{C}$ then to convert them into pellet thickness of $1 \mathrm{~mm}$.

\section{Results and interpretation}

\subsection{Structure and morphology stability of PANI/ Mmt nanocomposite in aggressive media}

We noticed that the mass loss increased with the residence time in the acid solution, the phenomenon is more rapid at $25^{\circ} \mathrm{C}$ but quantitatively more significant at $80^{\circ} \mathrm{C}$. We also noted that this weight loss was greater in the case of PANI ES aged under the same conditions. The difference is on average $2-3 \%$. We conclude that the presence of clay reduces the departure oligomers and therefore reserve the sample from the corrosive effects of acidic solutions (Fig. 2). 
Fig. 3 DRX of PANI/Mmt nanocomposite synthesized in a $1 \mathrm{M}$ $\mathrm{HCl}$ solution

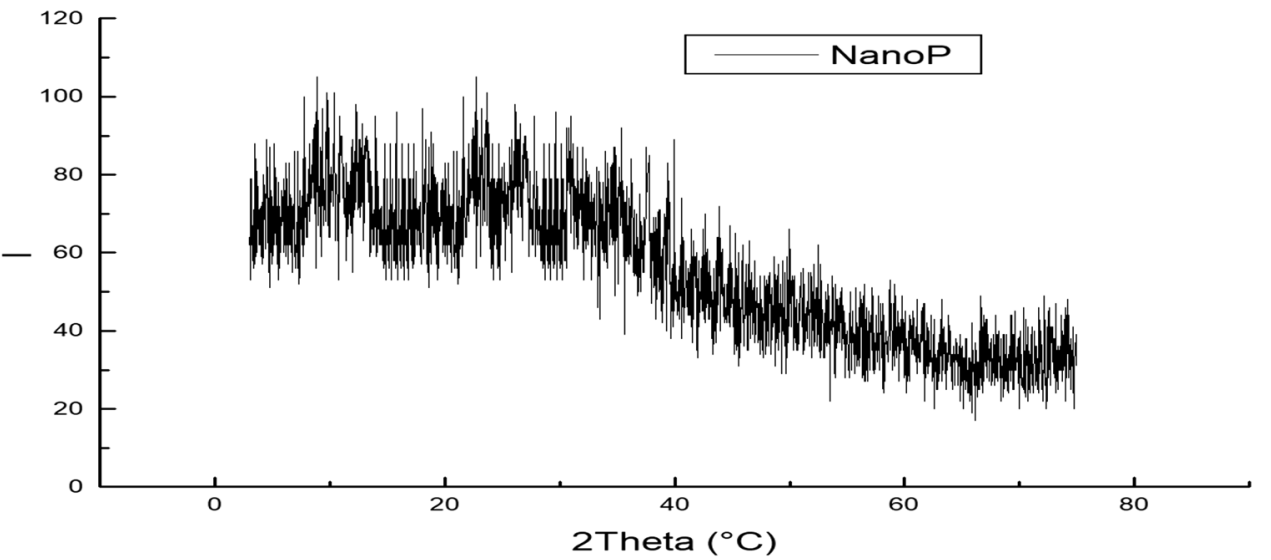

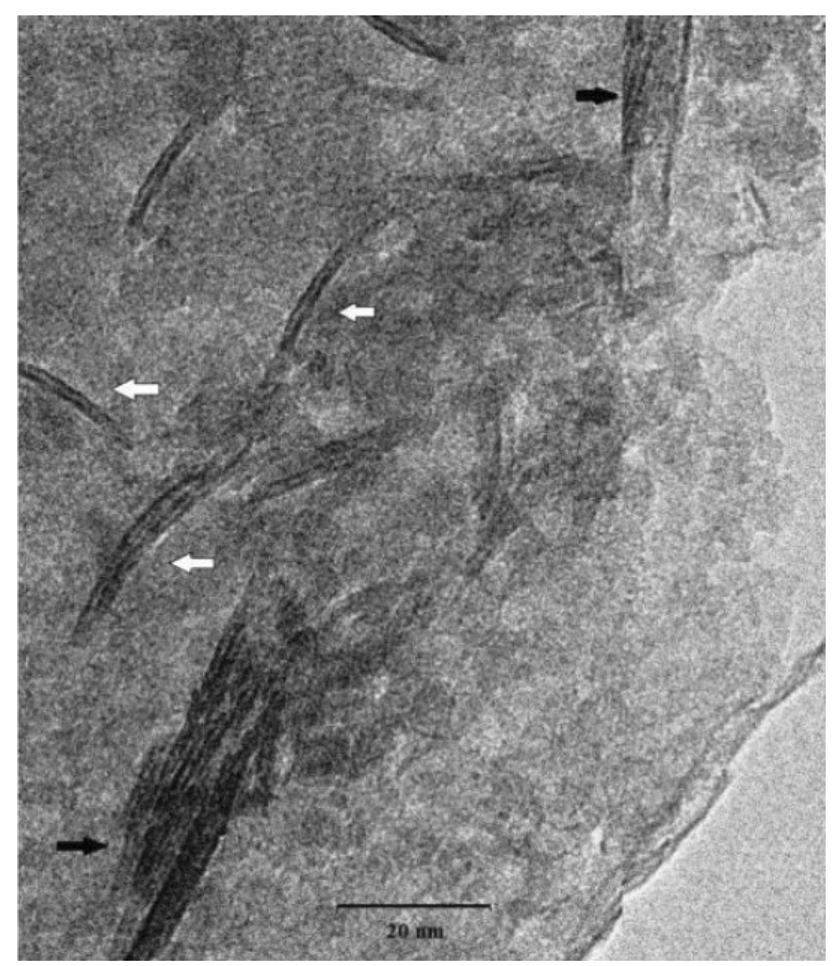

Fig. 4 TEM image of PANI/Mmt nanocomposite; white arrow: exfoliated layers, black arrow: intercalated layers

On the diffractogramme (Fig. 3), the absence of the peaks of diffraction is clearly what ensures an exfoliate structure of the PANI/Mmt nanocomposites. This statement is confirmed by transmission electronic microscopy, Fig. 4 shows exfoliate layers dispersed in the matrix, and the agglomerates layers intercalated by the PANI $[32,33]$.
We observe on the diffractogram of PANI/Mmt nanocomposite degraded 3 months in aggressive media (Fig. 5), the disappearance of the first diffraction peak of the montmorillonite organophilic characteristic of the interlayer distance $\left(\mathrm{d}_{001}\right)$, the layers do not show any crystalline organization, the interlayer distance becomes greater than that measured by X-rays diffraction, the clay layers are individualized and dispersed in the matrix, therefore the sample has an exfoliated structure $[32,33]$.

The infra-red spectrum on Fig. 6 revealed the existence of the two phases of organics and inorganics visibly [34-37], show the same absorption bands as that of PANI ES6 with an additional peak corresponding to the bond $\mathrm{Si}-\mathrm{O}$ located at $1060 \mathrm{~cm}^{-1}$ characteristic of clay.

The FTIR spectra of simple after degradation for 3 months in acidic media (Fig. 7) did not show any structure changes of the nanocomposites polyaniline/Mmt org. Figure 7 revealed two intense tops at $1567 \mathrm{~cm}^{-1}$ and $1491 \mathrm{~cm}^{-1}$ corresponding respectively to the shifts of bond valence by vibrations of the cycles quinoïde $(C=N)$ and the cycles benzoïdes ( $\mathrm{C}-\mathrm{N})$.

The micrograph AFM (Fig. 8a) illustrates clearly the surface quality [37] of PANI/Mmt nanocomposite, the results of microanalyses AFM reveals the topographic state of the nanocomposite rigorous surface however not the influence of surface degradation, it does not have any contrast there on the image in phase mode, which means that the relief of surface, is the same after 4 months of thermal degradation under the sulphuric acid, our nanocomposite is always meadows use. Moreover the micrograph of the height mode gives a deep distance of $Z=1.2 \mu \mathrm{m}$, which is near to that of the nanocomposite before degradation (Fig. 8b, c). This conclusion is affirmed by the histogram on Fig. $8 \mathrm{~d}$ which reveals no change of the value roughness $\mathrm{RMS}=0.1721$. 
Fig. 5 DRX of PANI/Mmt nanocomposite degraded 3 months in aggressive media

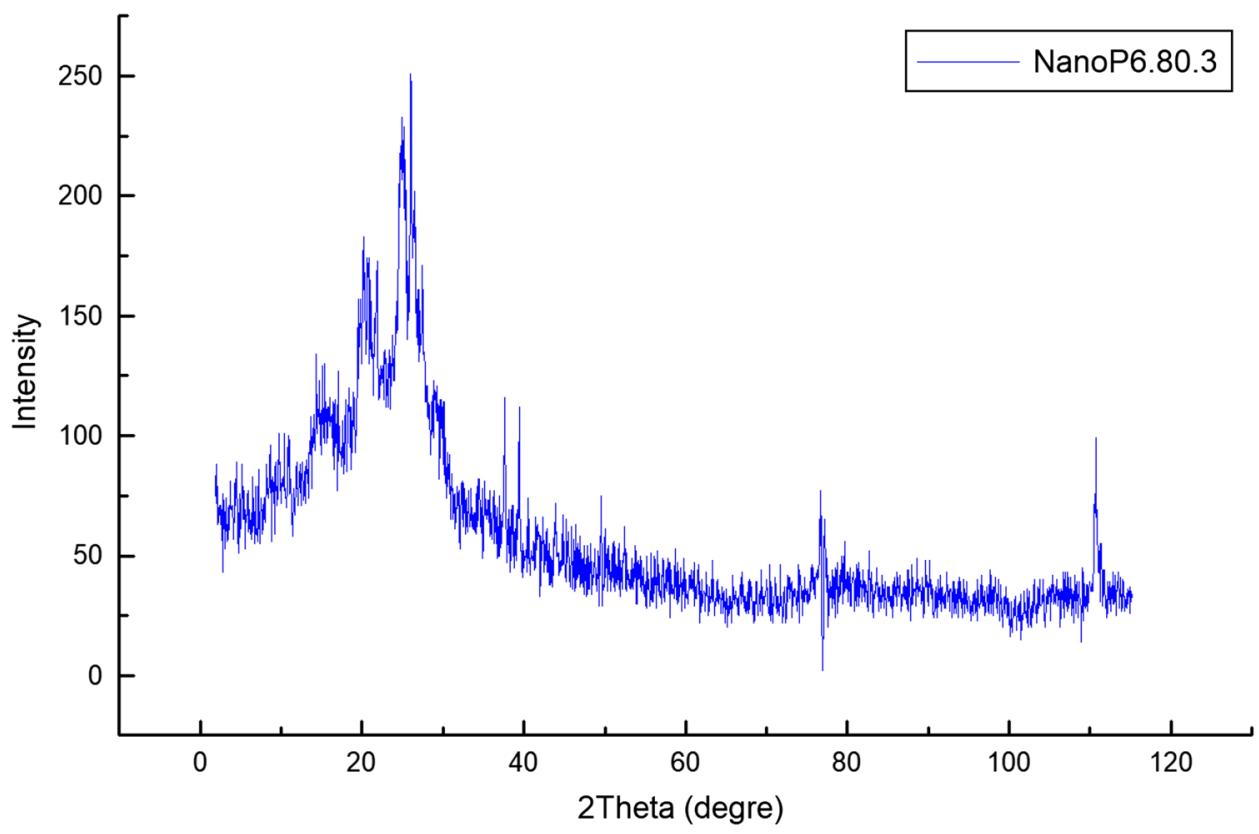

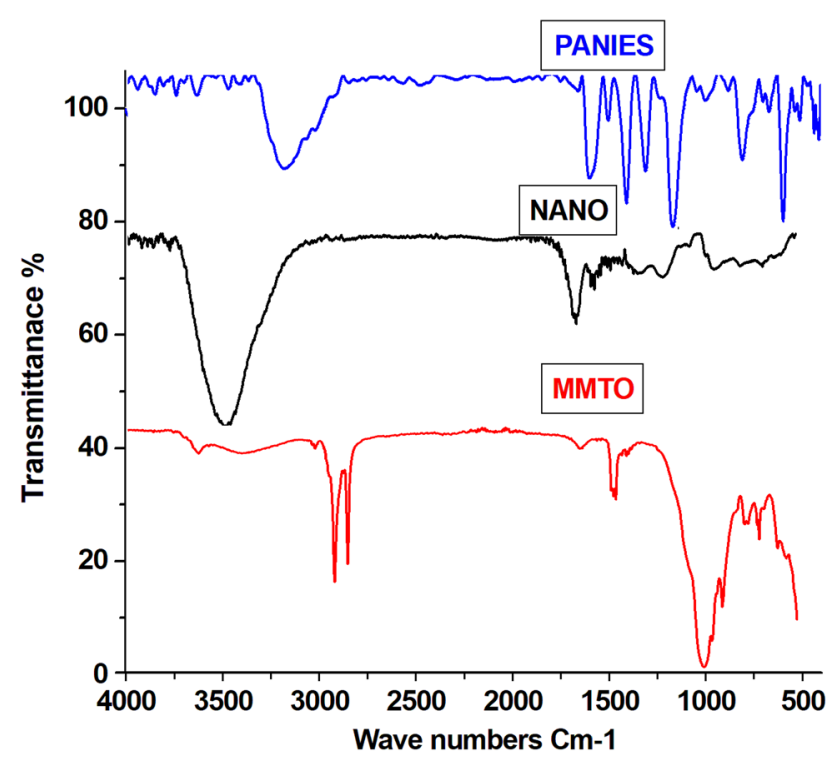

Fig. 6 FTIR spectra of PANI/Mmt nanocomposite, PANI and Mmtorg

\subsection{Thermal stability of PANI/Mmt nanocomposite in aggressive media}

PANI/Mmt nanocomposites were investigated by thermogravimetric analysis (TGA) and we compared this results with that of the PANI.

For all the samples, the initial weight loss is slightly observed at nearly $110^{\circ} \mathrm{C}$, it is due to the loss of moisture [38], and it represents approximately $5 \%$ of initial weight

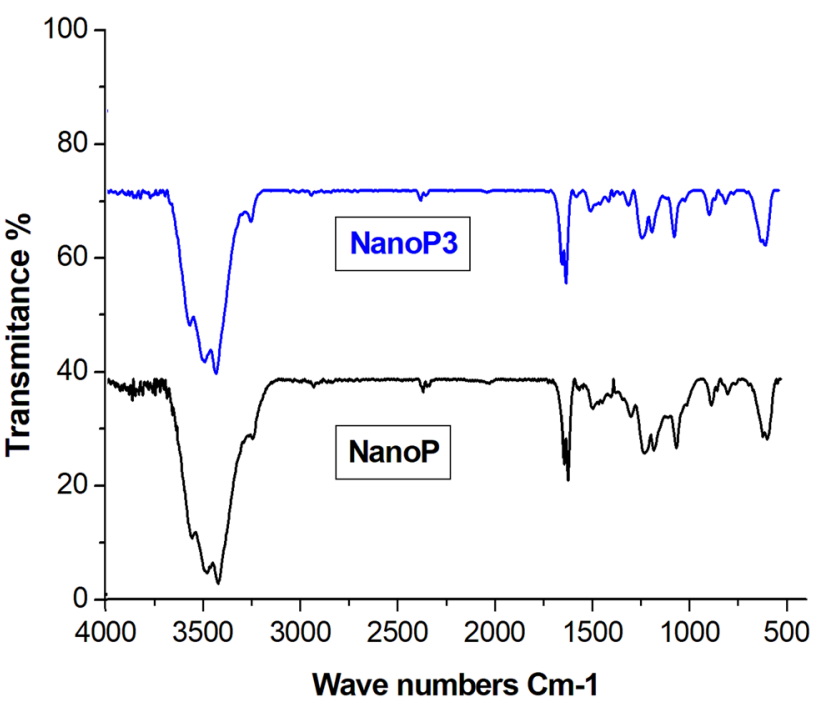

Fig. 7 FTIR spectrum of NanoPANI6 803 degraded for 3 months

of the product. The mass decrease is observed between 204 and $328^{\circ} \mathrm{C}$ for organophilized Montmorillonite and nanocomposite (NanoPANI6), this behavior is associated with the elimination of $\mathrm{HCl}$ and the decomposition of Surfactants which is degraded in this interval [39]. The mass loss recorded equal to $29 \%$. It is noticed that the loss of the doping agent is delayed in the NanoPANI6 sample compared with polymer.

The principal loss masses in both nanocomposite and PANI6 correspond to the decomposition of the matrix 
a

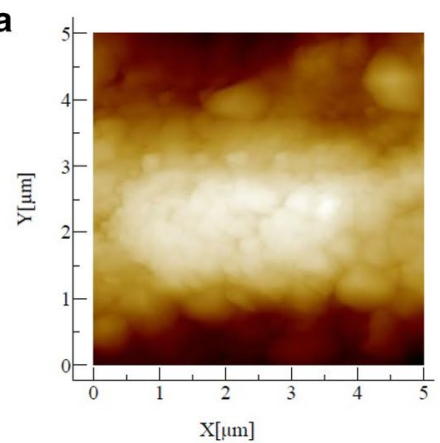

b

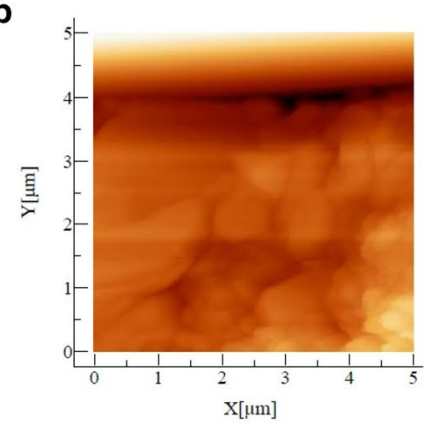

C

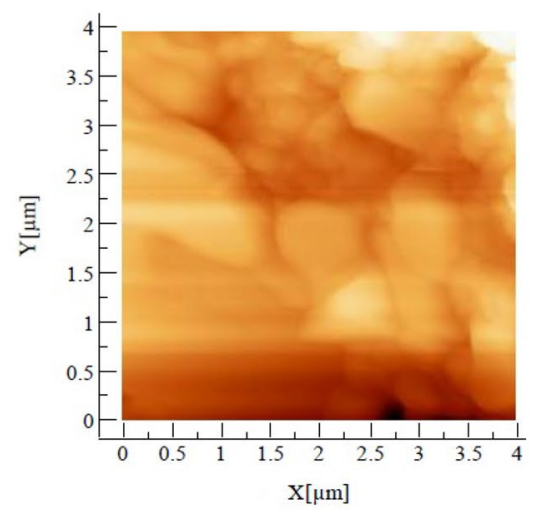

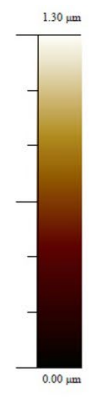


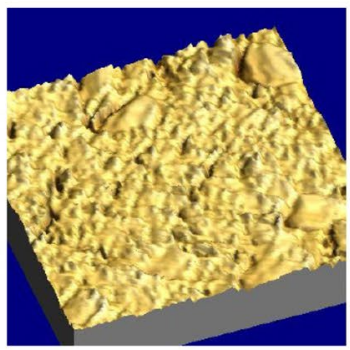

$1.20 \mu \mathrm{m}$
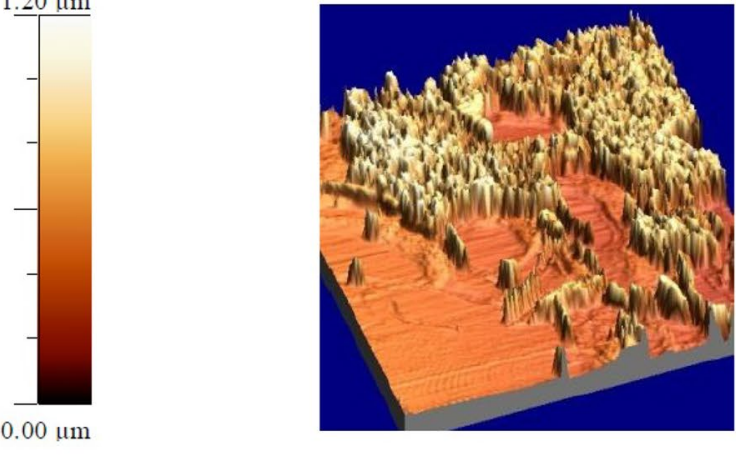

d
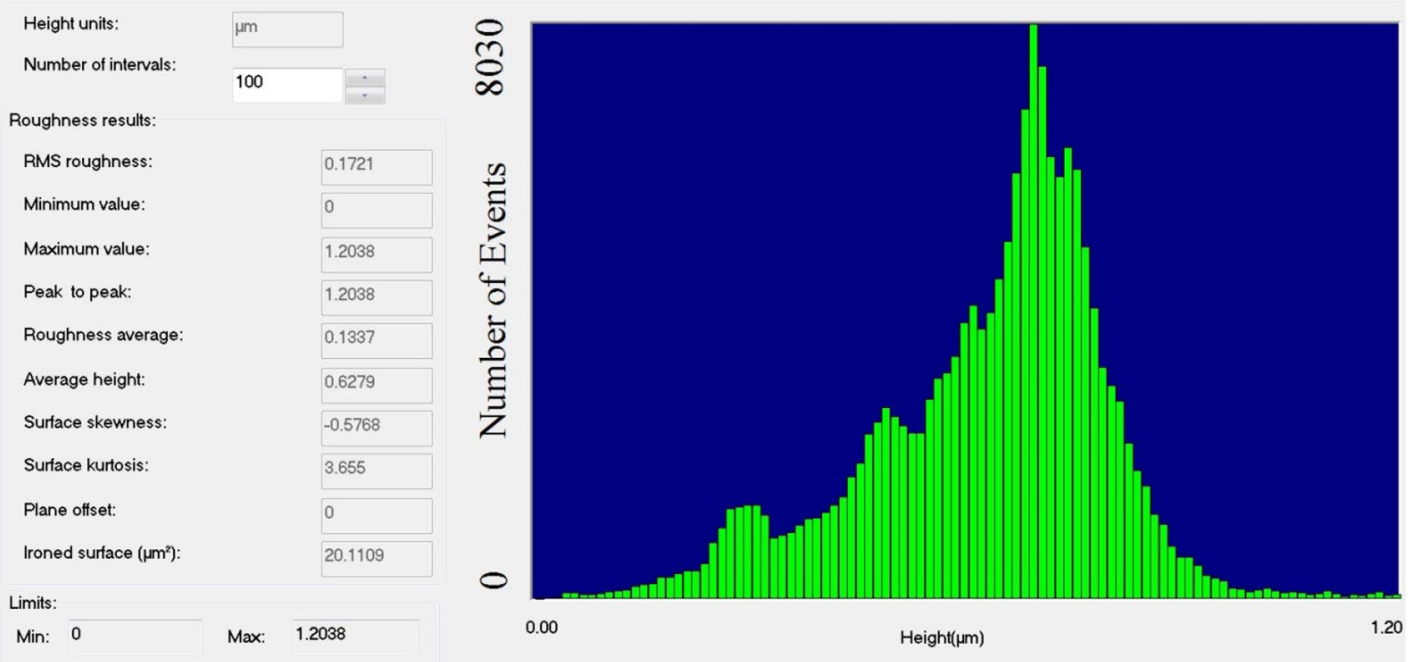
4 Fig. 8 a Atomic force micrograph of PANI/Mmt nanocomposite with $512 p$ resolution. Left: $2 D$ image $(x, y)$ and the depth $Z=1.30 \mu \mathrm{m}$. A right: 3D image. Middle: 3D image in phase mode. $\mathbf{b}$ Atomic force micrograph of nanocomposite PANI6 254 with $512 p$ resolution. Left: $2 D$ image $(x, y)$ and the depth $Z=1.89 \mu \mathrm{m}$. A right: $3 \mathrm{D}$ image. Middle: 3D image in phase mode. c Atomic force micrograph of nanocomposite PANI6 804 with 512p resolution. Left: 2D image $(x, y)$ and the depth $Z=1.89 \mu \mathrm{m}$. A right: 3D image in phase mode. d Atomic force micrograph of nanocomposite PANI6 804 2D $(x, y)$ with the depth $Z=1.2 \mu \mathrm{m}$

PANI which begins at $450{ }^{\circ} \mathrm{C}$ in the NanoPANI6 sample. This temperature is definitely higher than that for polyaniline whose decomposition starts towards $420^{\circ} \mathrm{C}$. The mass loss recorded for the NanoPANI6 sample is of $10 \%$. Compared to $17.4 \%$ for PANI6, the nanocomposites are thermally stable up to the PANI (Fig. 9). This increase in thermal stability of the nanocomposites is justified by the barrier effect of the clay layers [35, 36]. During the decomposition, the oxygen gas and molecules resulting from the products distribute more slowly, slowed down in their ways by the clay layers dispersed in the polymeric matrix [39-44] so degradation is prolonged and a thermal behavior increases. The nanocomposites charged with a value $>5 \%$ show a more stable thermal behavior because the clay concentration is more, the thermal barrier effect is more important and tortuosity is accentuated but that with detriment of the conductivity of material.

The differential thermal analysis DTA of NanoPANI6 and PANI6 is confirmed by exothermic pick in the various intervals of TGA mass loss (Fig. 10).

After the synthesis of our Nanocomposite, we prepare solutions concentrated of $5 \mathrm{M} \mathrm{HCl}$ then put $3 \mathrm{mg}$ of this Nanocomposite in $30 \mathrm{ml}$ of this concentrated solution under a temperature of $80^{\circ} \mathrm{C}$ for 3 months, we obtain the sample Nano PANI6 803.

Thermogram TG of Nanocomposite PANI6 803 (Fig. 11) presents a three level profile, it shows two weight losses. We observe initially, the gradual weak mass loss between 50 and $110^{\circ} \mathrm{C}$ resulting from elimination of hygroscopic water, it represents approximately $3 \%$ of initial weight of the product dried one night in a drying oven at $50^{\circ} \mathrm{C}$. A second mass loss is recorded in the interval of temperatures from 255 to $614{ }^{\circ} \mathrm{C}$ and represents weight loss of $45 \%$. It is allotted to the decomposition of the material.

Thermogravimetric analysis and differential thermal analysis (Fig. 12) of the nanocomposite PANI6 803 shows the similarity with that of initial nanocomposite. It is thus noted that this material is stable during 3 months of degradation in a strongly acid medium with a high temperature.
Figure 13 represents thermogram DSC of the PANI-Mmt nanocomposite. We observe a first endothermic peak at $155^{\circ} \mathrm{C}$ characteristic of evaporating physically absorbed water. The peak located at $245^{\circ} \mathrm{C}$ is allotted to the relaxing of the polymeric chains. The presence of endothermic peak at $300{ }^{\circ} \mathrm{C}$ is related to elimination of the HDTMAB. The crosslinked chains of the PANI in the nanocomposite manifest itself towards $360{ }^{\circ} \mathrm{C}$ and is thus tardy compared to the PANI for the reason that there is presence of clay. This phenomenon is followed by decomposition of the polyaniline which starts towards $430^{\circ} \mathrm{C}$ in nanocomposite whereas it was initiated at $415^{\circ} \mathrm{C}$ in the PANI.

Nanocomposite (NanoPANI6 80 3) degraded for 3 months in a corrosive media at temperature of $80^{\circ} \mathrm{C}$ present, on Fig. 14 same peaks as the NanoPANI6, which reflects opposite stability under these conditions.

We measured the lost mass of NanoPANI6 aged at temperature of $265^{\circ} \mathrm{C}$ during $10 \mathrm{~h}$ under atmosphere of nitrogen, shows a very great stability estimated on the thermogram, only mass loss was observed, it is negligible and related to the separation of moisture with time (Fig. 15).

\subsection{Evolution of the electric conductivity}

\subsubsection{Electrical conductivity stability of Nanocomposite according the time of degradation in different temperature}

We followed the effects of the application constraints like thermal degradation and on aggressive solutions for the period of 6 months on uncharged Materials and charged nanocomposite, followed by measure of Electrical conductivity during this degradation (Table 2).

The electrical conductivity of the nanocomposite is definitely inferior to that of the PANI6 but this variation after thermal degradation under the corrosive conditions is negligible because of the barrier effect of the clay reinforcement.

\subsubsection{Influence of temperature on electrical conductivity}

After that, we undertook the influence of temperature on synthesized materials, by accelerating thermal degradation at various temperatures during 30 days in a drying oven. Then measurement of electrical conductivity is necessary for the visibility of the study.

The temperatures of degradation used are 60, 80, 100, 150 and $200^{\circ} \mathrm{C}$.

The results presented in Table 3 show that electrical conductivity is verily influenced by the temperature. 
Fig. 9 Thermogram TG of PANI/Mmt nanocomposite
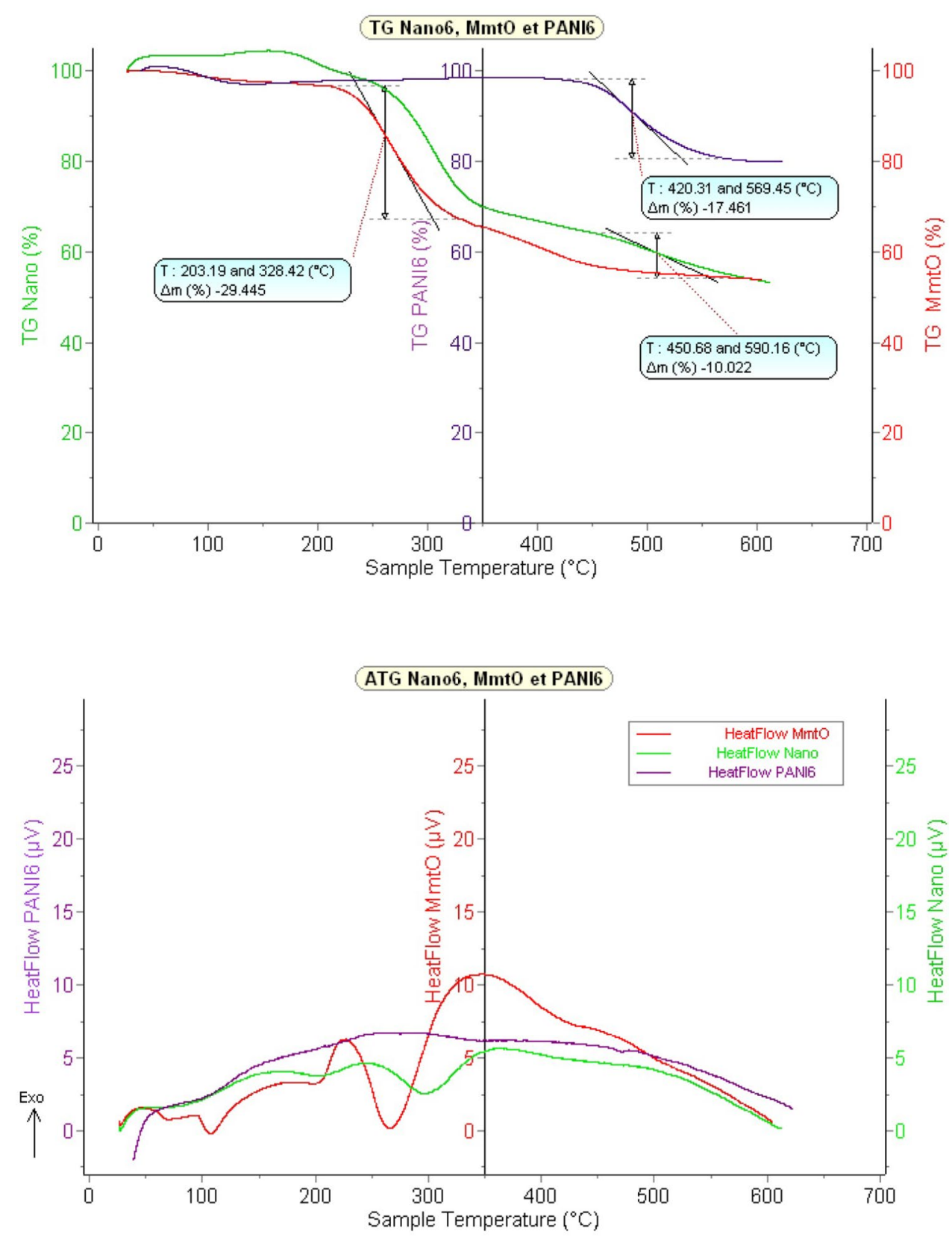

Fig. 10 Thermogram ATD of PANI/Mmt nanocomposite marked towards $200{ }^{\circ} \mathrm{C}$. This protonation loss of PANI made the material become gradually non-conducting. This phenomenon of loss of doping agent is differed in the nanocomposites.

According to the results brought back on Fig. 16. We see that with room temperature, for the selected samples (PANI, nanocomposite), the electric conductivity decreases slowly when the contact duration increases. This decrease is however less important for the charged samples. 
Fig. 11 Thermogram ATG of nanocomposite PANI6 803
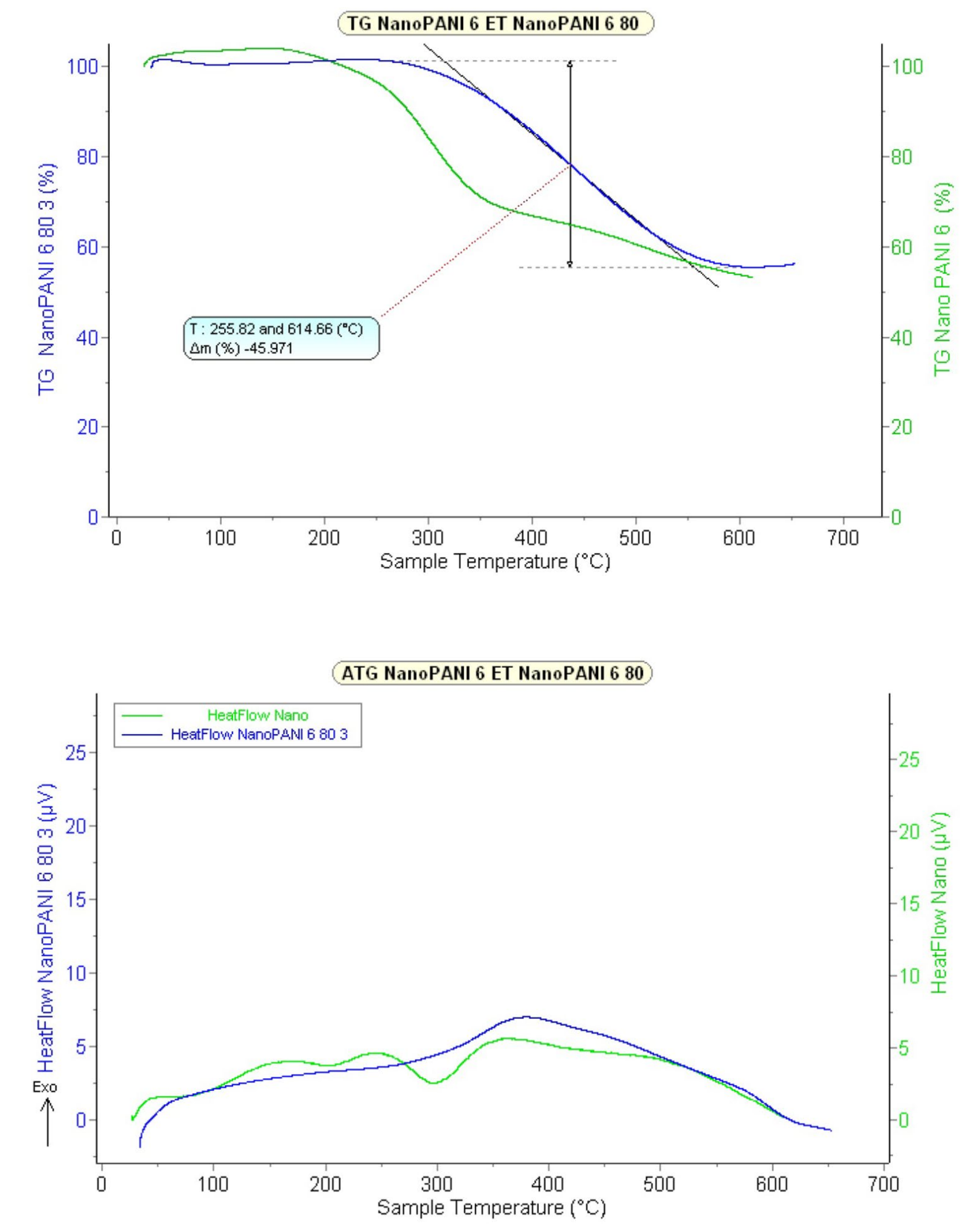

Fig. 12 Thermogram ATD of the nanocomposite PANI6 803
But at high temperature $\left(120^{\circ} \mathrm{C}\right)$, the profiles of the curves diverged. The conductivity of the PANI decreases noticeably after more than 30 days of exposure, the loss is higher than $85 \%$. It is cancelled after 45 days. That of nanocomposites seems more stable, it decreases more slowly than that of PANI. The loss of conductivity reaches $72 \%$ in 60 days of exposure for nanocomposites.

We can conclude that the nanocomposites have conductivity more stable in time when the temperature increases.

\subsubsection{Study of the conductivity of NanoPANI6 according to the clay rate added}

The more the rate of Mmt-org increases and the more conductivity decreases, that is interpreted by the fact that Mmt-org forms an electrical barrier which prevents the current passing as shown in the Fig. 17 [45-48]. The displacement of the electric charge through the polyaniline is done by a proton along the chain of polymer (Fig. 18), this is why conductivity is significant, however in nanocomposite the electric transport is stopped by the obstacles of $5 \%$ 
Fig. 13 Thermogram DSC of PANI/Mmt nanocomposite
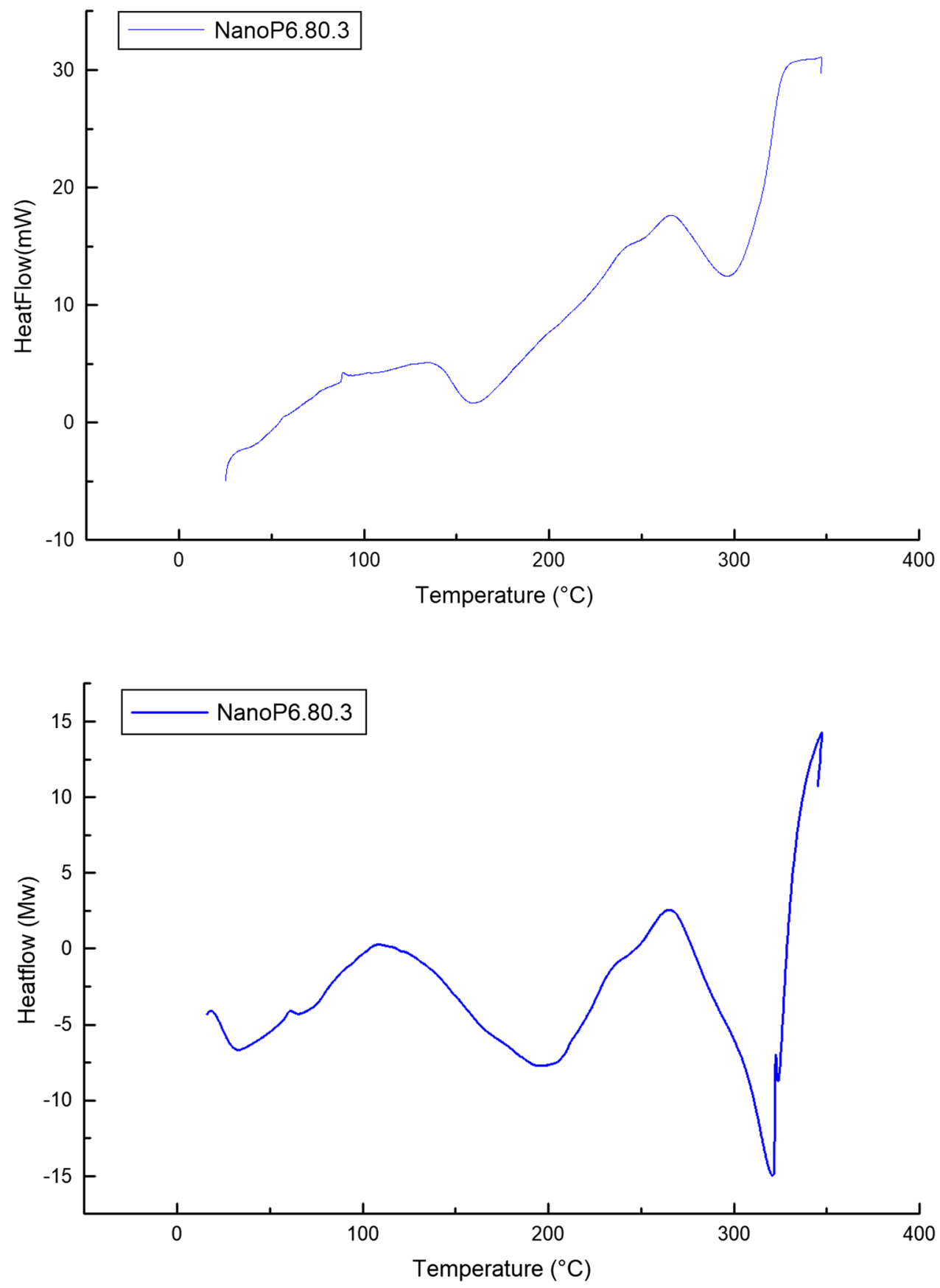

phyllosilicates. The break-even seems located towards 5\%, after this critical report, conductivity decreases clearly with several magnitudes. In this case, the clay particles are a cause of this reduction. The need of connectivity between the chains of PANI separated by the clay particles, limits inter-chains transport.

\section{Conclusion}

In this work, we wanted to increase the fundamental knowledge of intrinsic conducting polymer and nanocomposite in order to improve their electrical properties for industrial applications. And also see the effect of corrosive media in high temperatures caused by these applications. 
Fig. 15 Stability thermique of $\mathrm{PANI} / \mathrm{Mmt}$ nanocomposite



Sample

Degradation period

Degradation temperature $\left({ }^{\circ} \mathrm{C}\right)$

electrical conductivity $(\mathrm{S} / \mathrm{cm})$

\begin{tabular}{lllll}
\hline NanoPANI6 & - & - & - & $1.3 \times 10^{-1}$ \\
NanoPANI6.1.25 & 1 & 25 & $\mathrm{HCl}$ & $1.22 \times 10^{-1}$ \\
NanoPANI6.2.25 & 2 & 25 & $\mathrm{HCl}$ & $1.10 \times 10^{-1}$ \\
NanoPANI6.3.25 & 3 & 25 & $\mathrm{HCl}$ & $1.12 \times 10^{-1}$ \\
NanoPANI6.4.25 & 4 & 25 & $\mathrm{HCl}$ & $1.20 \times 10^{-1}$ \\
NanoPANI6.6.25 & 6 & 25 & $\mathrm{HCl}$ & $1.02 \times 10^{-1}$ \\
NanoPANI6.1.80 & 1 & 80 & $\mathrm{HCl}$ & $1.18 \times 10^{-1}$ \\
NanoPANI6.2.80 & 2 & 80 & $\mathrm{HCl}$ & $1.11 \times 10^{-1}$ \\
NanoPANI6.3.80 & 3 & 80 & $\mathrm{HCl}$ & $0.98 \times 10^{-1}$ \\
NanoPANI6.4.80 & 4 & 80 & $\mathrm{HCl}$ & $0.92 \times 10^{-1}$ \\
NanoPANI6.6.80 & 6 & 80 & $\mathrm{HCl}$ & $1.0 \times 10^{-1}$ \\
\hline
\end{tabular}

Table 3 Electrical conductivity of the samples subjected to a heat treatment

\begin{tabular}{lll}
\hline $\begin{array}{l}\text { Temperature degrada- } \\
\text { tion }\left({ }^{\circ} \mathrm{C}\right)\end{array}$ & \multicolumn{2}{l}{ Conductivity $(\mathrm{S} / \mathrm{cm})$} \\
\cline { 2 - 3 } & PANI-ES & Nanocomposite \\
\hline $\begin{array}{l}\text { Before the thermodeg- } \\
\text { radation }\end{array}$ & 1.23 & $1.3 \times 10^{-1}$ \\
80 & 1.1 & $1.2 \times 10^{-1}$ \\
100 & $1.5 \times 10^{-1}$ & $5.4 \times 10^{-2}$ \\
150 & $8.4 \times 10^{-4}$ & $5.6 \times 10^{-4}$ \\
200 & $5 \times 10^{-6}$ & $0.21 \times 10^{-6}$ \\
\hline
\end{tabular}

The continuation of this work was devoted to electric characterizations study by the method of the four points and to see its thermal behavior using the thermal analysis ATD-ATG and DSC.

The experimental results of thermal and electrical stability of polyaniline during 6 months defined the lifetime under very difficult conditions.

The nanocomposite showed a better stability in extreme degradation following the barrier effect caused by the clay layers dispersed in polymer but it has at the beginning a less electric conductivity. 

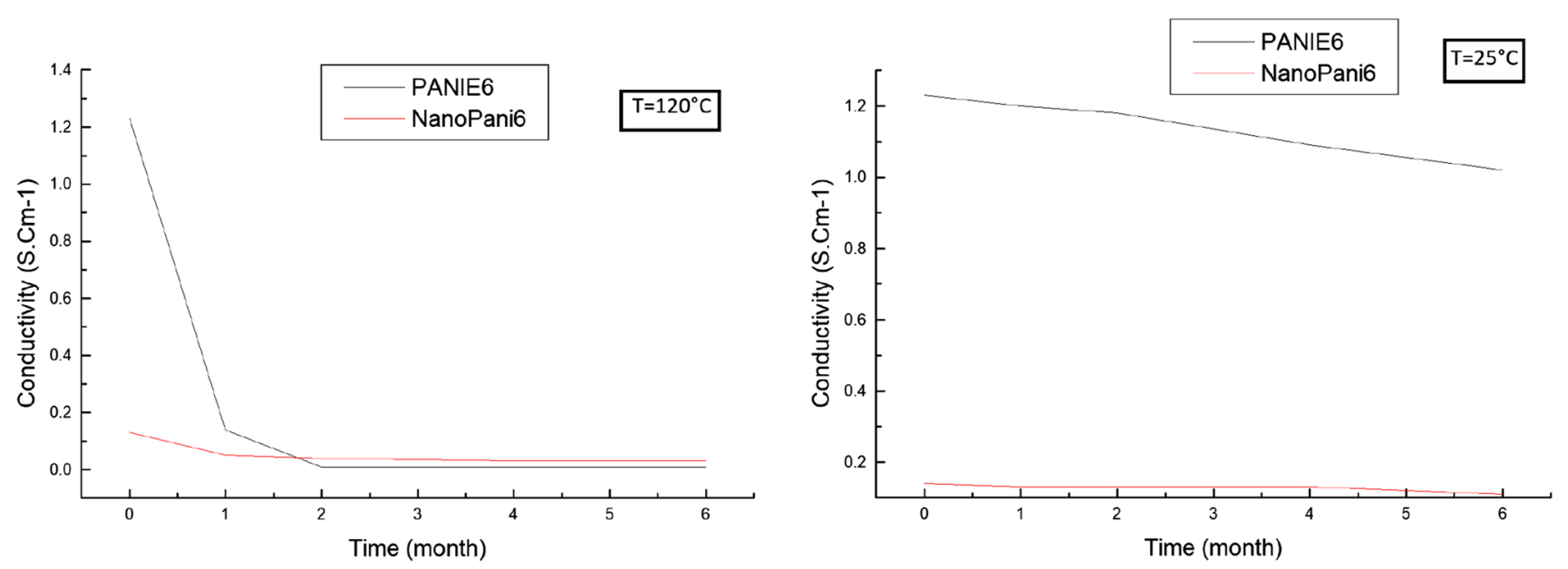

Fig. 16 Evolution of the electrical conductivity of PANI and nanocomposite as a function of time

Fig. 17 Electrical conductivity of the nanocomposite as a function of \% clay

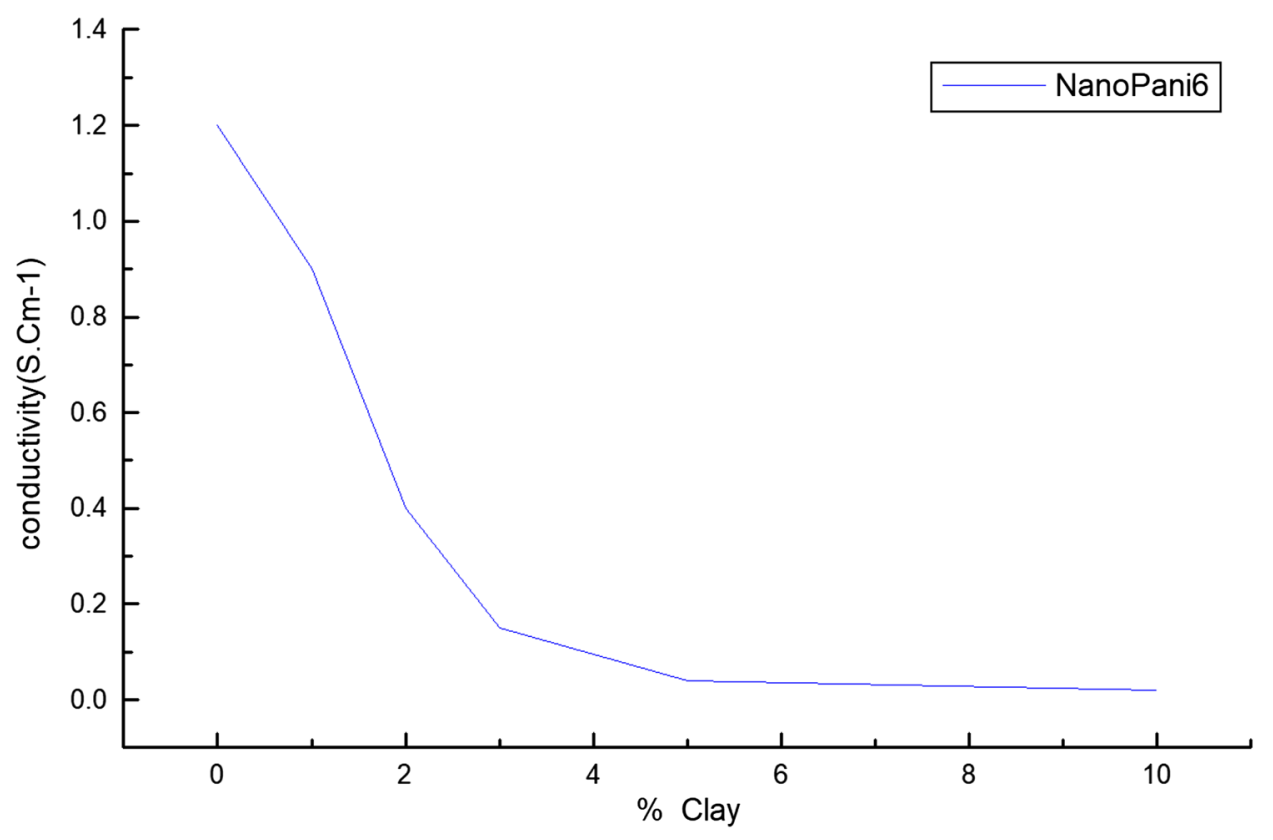

This work shows the interest of diversity characterizations for the study of these materials. Indeed, characterizations defined the state of material during the time of use as cathode in the battery or anti-corrosive painting for the pipeline which respectively requires a strongly acid medium with relatively high temperature. For the continuation of this work, it would be interesting to use the strong sensitivity of measurements to degradation study of the samples and to obtain further information concerning the ways of conduction. 

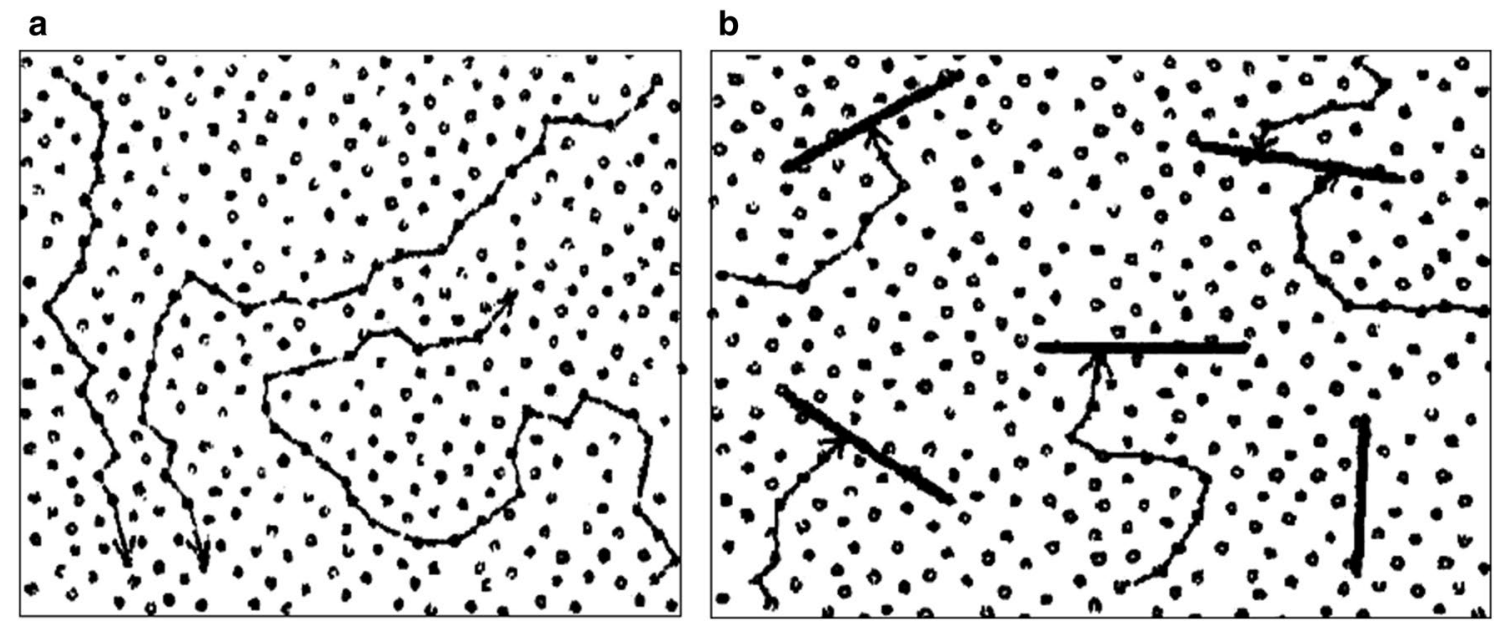

Fig. 18 Connectivity PANI chains separated by the clay particles

\section{Compliance with ethical standards}

Competing interest The authors (HATTAB Youcef and BENHARRATS Nassira) declare that they have no conflict of interest.

\section{References}

1. Huang Z, Lin Z, Cai Z, Mai K (2004) Physical and mechanical properties of nano- $\mathrm{CaCO}_{3} / \mathrm{PP}$ composites modified with acrylic acid. Plast Rubber Compos 33:343-346

2. Lu Y, McLellan J, Xia Y (2004) Synthesis and crystallization of hybrid spherical colloids composed of polystyrene cores and silica shells. Langmuir 8:3464-3470

3. Bhanvase BA, Sonawane SH (2009) New approach for simultaneous enhancement of anticorrosive and mechanical properties of coatings: application of water repellent nano $\mathrm{CaCO}_{3}-\mathrm{PANI}$ emulsion nanocomposite in alkyd resin. Chem Eng J 156:177-183

4. Bhanvase BA, Gumfekar SP, Sonawane SH (2009) Water based PMMA-nano- $\mathrm{CaCO}_{3}$ nanocomposite by in-situ polymerization technique: synthesis, characterization and mechanical properties. Polym Plast Technol Eng 48:939-944

5. Bhanvase BA, Pinjari DV, Gogate PR, Sonawane SH, Pandit AB (2011) Process intensification of encapsulation of functionalized $\mathrm{CaCO}_{3}$ nanoparticles using ultrasound assisted emulsion polymerization. Chem Eng Process Process Intensif 50:1160-1168

6. Bhanvase BA, Pinjari DV, Gogate PR, Sonawane $S H$, Pandit AB (2012) Synthesis of exfoliated poly(styrene-co-methyl methacrylate)/Mmt nanocomposite via ultrasound assisted in-situ emulsion copolymerization. Chem Eng J 181-182:770-778

7. Caruso F (2001) Nanoengineering of particle surfaces. Adv Mater 13:11-22

8. Ma L, Hendrickson KE, Wei S, Archer LA (2015) Nanomaterials: science and applications in the lithium-sulfur battery. Nano Today 10:315-338

9. Zhao H, Yuan W, Liu G (2015) Hierarchical electrode design of high-capacity alloy nanomaterials for lithium-ion batteries. Nano Today 10:193-212

10. Pud A, Ogurtsov N, Korzhenko A, Shapoval G (2003) Some aspects of preparation methods and properties of polyaniline blends and composites with organic polymers. Prog Polym Sci 28:1701-1753

11. Li XG, Li A, Huang MR (2008) Facile high-yield synthesis of polyaniline nanosticks with intrinsic stability and electrical conductivity. Chem A Eur J 14(33):10309-10317

12. Li XG, Li A, Huang MR, Liao Y, Lu YG (2010) Efficient and scalable synthesis of pure polypyrrole nanoparticles applicable for advanced nanocomposites and carbon nanoparticles. J Phys Chem C 114(45):19244-19255

13. Li XG, Li J, Huang MR (2009) Facile optimal synthesis of inherently electroconductive polythiophene nanoparticles. Chem A Eur J 15(26):6446-6455

14. Li XG, Lü QF, Huang MR (2008) Self-stabilized nanoparticles of intrinsically conducting copolymers from 5-sulfonic-2-anisidine. Small 4(8):1201-1209

15. Li XG, Feng H, Huang MR, Gu GL, Moloney MG (2012) Ultrasensitive $\mathrm{Pb}$ (II) potentiometric sensor based on copolyaniline nanoparticles in a plasticizer-free membrane with a long lifetime. Anal Chem 84(1):134-140

16. Gonzalez-Rodriguez JG, Lucio-Garcia MA, Nicho ME, Cruz-Silva $R$, Casales M, Valenzuela $E$ (2007) Improvement on the corrosion protection of conductive polymers in pemfc environmets by adhesives. J Power Sources 186:184-190

17. Jeyaprabha C, Sathiyanarayanan S, Venkatachari G (2006) Effect of cerium ions on corrosion inhibition of PANI for iron in $0.5 \mathrm{M} \mathrm{H}_{2} \mathrm{SO}_{4}$. Appl Surf Sci 253:432-438

18. Zhong L, Zhu H, Hu J, Xiao S, Gan F (2006) A passivation mechanism of doped polyaniline on 410 stainless steel in deaerated $\mathrm{H}_{2} \mathrm{SO}_{4}$ solution. Electrochim Acta 51:5494-5501

19. Dispenza C, Lo Presti C, Belfiore C, Spadaro G, Piazza S (2006) Electrically conductive hydrogel composites made of polyaniline nanoparticles and poly ( $N$-vinyl-2-pyrrolidone). Polymer 47:961-971

20. Abu YM, Aoki K (2005) Corrosion protection by polyanilinecoated latex microspheres. J Electroanal Chem 583:133-139

21. Fang Q, Chetwynd DG, Covington JA, Toh CS, Gardner JW (2002) Micro-gas-sensor with conducting polymers. Sens Actuators B 84:66-71

22. Janata J, Josowicz M (2003) Conducting polymers in electronic chemical sensors. Nat Mater 2:19-24

23. Negi YS, Adhyapak PV (2002) Development in polyaniline conducting polymers. J Macromol Sci Polym Rev 42:35-53 
24. Geng L, Zhao Y, Huang X, Wang S, Zhang S, Wu S (2007) Characterization and gas sensitivity study of polyaniline $/ \mathrm{SnO}_{2}$ hybrid material prepared by hydrothermal route. Sens Actuators B 120:568-572

25. Barkade SS, Naik JB, Sonawane SH (2011) Ultrasound assisted miniemulsion synthesis of polyaniline/Ag nanocomposite and its application for ethanol vapor sensing. Colloids Surf $A$ 378:94-98

26. Kulhánková L, Tokarský J, Matějka V, Peikertová P, Vallová S, Mamulová Kutláková K, Stýskala V, Čapková P (2014) Electrically conductive and optically transparent polyaniline/ montmorillonite nanocomposite thin films. Thin Solid Films 562:319-325

27. Rather MS, Kowsar M, Wanchoo RK, Singla ML (2013) Nanocomposite of polyaniline with the photoadduct of potassium hexacyanoferrate and pyridine ligand: structural, electrical, mechanical and thermal study. Synth Met 179:60-66

28. Jaymand $M$ (2011) Surface modification of montmorillonite with novel modifier and preparation of polystyrene/montmorillonite nanocomposite by in situ radical polymerization. J Polym Res 18:957-963

29. Dong YP, Ding Y, Zhou Y, Chen J, Wang CM (2014) Differential pulse anodic stripping voltammetric determination of $\mathrm{Pb}$ ion at a montmorillonites/polyaniline nanocomposite modified glassy carbon electrode. J Electroanal Chem 717-718:206-212

30. Nath AK, Kumar A (2015) $100 \mathrm{MeV} \mathrm{Si}^{9+}$ swift heavy ion irradiation induced enhancement in electrochemical properties of electrolyte membrane composites based on ionic liquid-polymernanocomposite. J Membr Sci 485:30-41

31. Akbarinezhad E, Ebrahimi M, Sharif F, Attar MM, Faridi HR (2011) Synthesis and evaluating corrosion protection effects of emeraldine base PANI/clay nanocomposite as a barrier pigment in zinc-rich ethyl silicate primer. Prog Org Coat 70:39-44

32. Ray SS, Okamoto M (2003) Polymer/layered silicate nanocomposites: a review from preparation to processing. Prog Polym Sci 28:1539-1641

33. Akbarinezhad E, Ebrahimi M, Sharif F, Ghanbarzadeh A (2014) Evaluating protection performance of zinc rich epoxy paints modified with polyaniline and polyaniline-clay nanocomposite. Coat Prog Org Coat 77:1299-1308

34. Saranya S, Kalai Selvan R, Priyadharsini N (2012) Synthesis and characterization of polyaniline/ $\mathrm{MnWO}_{4}$ nanocomposites as electrodes for pseudocapacitors. Appl Surf Sci 258:4881-4887

35. Navarchian $A H$, Joulazadeh $M$, Karimi $F(2014)$ Investigation of corrosion protection performance of epoxy coatings modified by polyaniline/clay nanocomposites on steel surfaces. Prog Org Coat 77:347-353

36. Li H, Xie K, Pan Y, Wang H, Wang H (2012) Study of the mechanism of the variable emissivity infrared electrochromic device based on polyaniline conducting polymer. Synth Met 162:22-25

37. Baldissera AF, Souza JF, Ferreira CA (2013) Synthesis of polyaniline/clay conducting nanocomposites. Synth Met 183:69-72

38. Brozová $L$ et al (2008) The stability of polyaniline in strongly alkaline or acidic aqueous media. Polym Degrad Stab 93:592-600

39. Hattab Y, Benharrats N (2015) Thermal stability and structural characteristics of PTHF-Mmt organophile nanocomposite. Arab J Chem 8:285-292

40. Tilki T, Karabulut O, Yavuz M, Kaplan A, Cabuk M, Takanoglu D (2012) Irradiation effects on transport properties of polyaniline and polyaniline/bentonite composite. Mater Chem Phys 135:563-568

41. Alves Marins J, Guenther Soares B (2012) A facile and inexpensive method for the preparation of conducting polyaniline-clay composite nanofibers. Synth Met 162:2087-2094

42. Felix JF, Barros RA, de Azevedob WM, da Silva EF (2011) X-ray irradiation: a non-conventional route for the synthesis of conducting polymers. J Synth Met 161:173-176

43. Wang S, Huang Z, Wang J, Li Y, Tan Z (2012) Thermal stability of several polyaniline/rare earth oxide composites (I): polyaniline/ $\mathrm{CeO}_{2}$ composites. JTherm Anal Calorim 107:1199-1203

44. Liu Z et al (2015) The influence of 3-methacryloxypropyltrimethoxysilane on thermostability, tensile behavior and water resistance of polyvinyl acetate/clay nanocomposite. Polym Sci Ser B 57(5):522-552

45. Bhanvase BA, Sonawane SH (2014) Ultrasound assisted in situ emulsion polymerization for polymer nanocomposite: a review. Chem Eng Process 85:86-107

46. Khana MMR, Wee YK, Mahmood WAK (2012) Effects of CuO on the morphology and conducting properties of PANI nanofibers. Synth Met 162:1065-1072

47. Saad A, Jlassi K, Omastová M, Chehimi MM (2017) Clay/conductive polymer nanocomposites. In: Clay-polymer nanocomposites, 1st edn. Elsevier, Cambridge, pp 199-237

48. Valapa RB, Loganathan S, Pugazhenthi G, Thomas S, Varghese TO (2017) An overview of polymer-clay nanocomposites. In: Clay-polymer nanocomposites, 1st edn. Elsevier, Cambridge, pp 29-81

Publisher's Note Springer Nature remains neutral with regard to jurisdictional claims in published maps and institutional affiliations. 